\title{
CORPORATE CONTROL THROUGH BOARD DISMISSALS AND TAKEOVERS
}

\author{
DAVID HirshleIFER AND ANJAN V. THAKOR \\ University of Michigan Business School \\ Ann Arbor, MI 48109-1234 \\ david.hirshleifer@ccmail.bus.umich.edu \\ AnjanThakor@ccmail.bus.umich.edu
}

This paper examines some policy issues related to the interaction between internal and external corporate control mechanisms-board dismissals and takeovers-by focusing on the information aggregation and other effects related to this interaction. We model the functioning of corporate control mechanisms as an example of a multilayered principal-agent relationship in which shareholders delegate the task of monitoring management quality to the board and rely on the external takeover market to provide additional disciplining of the manager as well as of the board. This gives rise to two effects: (1) a substitution effect, whereby the takeover market partially substitutes for board dismissal of the manager, leading to greater lenience toward the manager by a board acting in the shareholders' best interest, and (2) a kick-in-the-pants effect, whereby the board is stricter with the manager because it may be dismissed by a successful acquirer who views it as lax. The interaction of these two effects leads to various implications about the behavior of boards and potential acquirers. In particular, a well-functioning internal control mechanism (the board) does not obviate the need for external control (takeovers). Moreover, somewhat counterintuitively, there may be a greater incidence of takeovers when the internal control mechanism is working well than when it is not.

\section{INTRODUCTION}

Our main objective is to examine the two major methods by which poorly performing managers of large corporations are removedforced resignation by the board of directors, and takeovers. ${ }^{1}$ These mechanisms clearly interact. The takeover market need only come into play when outside acquirers consider the monitoring decisions of

We thank an anonymous referee and the editor, Dan Spulber, for helpful comments.

1. DeAngelo and DeAngelo (1989) found that proxy contests are very frequently followed by management changes, but that these changes often occur through takeover or turnover even when dissidents are not elected to the board.

(C) 1998 Massachusetts Institute of Technology.

Journal of Economics \& Management Strategy, Volume 7, Number 4, Winter 1998, 489-520 
the board to be inadequate. Many have noted the important role played by the board in monitoring managers on behalf of shareholders (e.g. Fama and Jensen 1983). Such delegation by shareholders is necessitated by the passivity of shareholders in monitoring management on their own, passivity that may stem from a variety of factors, including the public-good problem of "rational ignorance" arising from coordination problems in collective action (see Black, 1992a, 1992b). Despite this potentially important role of the board, much of the research focus has been on the external market for corporate control.

This is perhaps because boards of directors have traditionally not been very vigilant in monitoring management, as exemplified by Peter F. Drucker's remark in Management: Tasks, Responsibilities and Practices (1993), "There is one thing all boards have in common-they do not function." In the last decade, however, boards of directors have apparently become more effective, possibly owing to increased risk of liability. For example, in the past few years the boards at Alcoa, Pillsbury, United Airlines (then Allegis), Kodak, Apple, GM, Mellon Bank, and DEC replaced their CEOs. ${ }^{2}$ Interest in the functioning of boards is clearly growing. An example is a cover story in a recent Business Week (Byrne, 1997) titled "The CEO and the Board," which discusses how the drive for corporate governance reform is beginning to focus on "lackluster" boards.

The resurgence of interest in the board's corporate governance role is attributable to the social costs of (hostile) takeovers as a mechanism for improving management. The implicit argument is that takeovers are necessary because of the ineffectiveness of boards of directors. Takeovers are, however, also a costly and imperfect means of correcting managerial failure. Thus, if boards became more effective, shareholders would need to rely less on takeovers, and takeover-related distortions (such as problems of short-term focus, as in Narayanan (1985) and Stein (1988), or excessive conservatism, as in Hirshleifer and Thakor (1992), could be reduced. If this argument is correct, its important policy implications for reducing the emphasis on legislatively-mandated takeover impediments relative to that on the internal corporate governance process are transparent.

Before we can conclude this, however, we must be cognizant of the hierarchical nature of agency relationships in publicly-owned

2. In its cover story, Business Week (July 3, 1989) quotes Kenneth Macke, CEO of Dayton-Hudson Corp.: "There's no question boards are more involved today. They are thinking through the process of corporate governance-what they're responsible for-and going into more detail about it." 
corporations. Managers are agents of boards of directors, who are themselves agents of shareholders, who in turn rely on potential acquirers to monitor the performances of both managers and boards. A noteworthy aspect of this relationship is that the shareholders face the moral hazard that a board may be too harsh in dismissing the top manager or that it may be too lax. It is plausible to conjecture that the board's own reputation for vigilance, the precision of its information about the manager's performance, and the efficacy of the takeover market determine how these two types of moral hazard are balanced. From a policy standpoint, it may thus be premature to conclude that a well-functioning board of directors obviates the need for an active takeover market in the corporate governance process.

This raises the following questions about the interaction between internal and external corporate governance:

- What will be the effect of increased takeover pressure on the behavior of the board of directors? Will it become stricter or more lenient in its decision to fire or retain the manager?

- How will the board's reputation affect the board's decision of whether to fire the manager?

- How does the informational precision of the board in evaluating the manager's performance affect its decision to replace him?

Since there exist empirical proxies for takeover pressure, board reputation, and the precision of the board's information the answers to these questions generate empirical implications as well as recommendations for managerial policy.

To answer these questions, we focus on three key features of the joint functioning of internal and external control mechanisms: information aggregation between boards and bidders, bidders' uncertainty about the vigilance of target boards, and the board's uncertainty about whether it will be retained following a successful takeover. Uncertainty about the vigilance of the board of directors is captured by assuming that the board may be one of two types, termed lax and vigilant. A lax board ignores internal signals of managerial performance and seeks to protect the manager's job to the extent possible. Thus, it never dismisses the manager. A vigilant board's incentive, on the other hand, is more closely aligned with that of the shareholders, although it too may display some aversion to a takeover because of the possibility that it will be displaced after a takeover. Such a board may dismiss the manager, and even if it retains him, it may accept a takeover bid, based on its own information about the manager in conjunction with information conveyed by the bid. 
We assume the board and potential bidders have different information, and that the information of each has value in assessing the performance of the CEO. The board's information is based on access to the CEO and internal information generated by the firm. A bidder can also possess information not subsumed by the information possessed by the board. For example, although the bidder does not possess the target's internal data, the bidder may be better informed than the board about industry conditions and the appropriateness of the firm's policies in view of these conditions. ${ }^{3}$

Our analysis is based on the related notions of information aggregation and sequential decisionmaking to deal with the efficiency issue of whether actual dismissal decisions optimally utilize the information of the board as well as the bidder. The role of takeovers in our model is replacement of inefficient manager. This external control mechanism comes into play only if the target firm's performance creates a suspicion of inefficiency and its manager is not fired by the board. In this sense, the board gets to move first by either retaining the manager or firing him. The vigilant board's decision is based in part on a noisy signal of managerial performance that it privately observes. A firing decision eliminates managerial inefficiency and ends the process. A retention decision leaves a potential acquirer - who privately receives an additional signal of managerial performance-with the option to make a bid for the firm. In deciding whether or not to bid, the potential acquirer makes a joint inference about the board's vigilance as well as its information regarding the manager, conditional on having observed retention. By the same token, in its own decision the vigilant board will take into account the fact that retaining the manager potentially permits its own information to be noisily aggregated with that of a candidate acquirer, whereas dismissal does not. This interaction is central to understanding the joint efficacy of internal and external control mechanisms.

The takeover market affects the behavior of a vigilant board in two ways. The first is a direct substitution effect. Having a takeover market means that some of the burden of replacing inefficient managers is shifted from the board to potential acquirers. The second is what we call a kick-in-the-pants effect. The presence of a takeover market means that a board that is lenient toward its manager may

3. The decision to fire is strongly influenced by outside board members, who may be outsiders such as academics with little specialized expertise in the industry (Weisbach, 1988). Hence the acquirer's "information" may really be knowledge accumulated over a long period that better enables it to interpret the most recent news about the manager's performance. 
have to pay a "personal price" for such lenience. In our model this "price" is manifested in the possible dismissal of the board itself after an acquirer takes over the firm and fires the manager. The motivation for this dismissal is the acquirer's belief that there is a sufficiently high probability that the board is lax. ${ }^{4}$ The interaction of the substitution and kick-in-the-pants effects allows us to address the questions raised earlier.

Although we analyze a variety of possible cases corresponding to various assumptions about exogenous parameters, if we focus on the cases in which the board is sufficiently concerned about being displaced after a takeover and the cost of firing the board is sufficiently low for an acquirer, then we find the following results.

- The threat of a takeover makes the board stricter in dismissing the manager. ${ }^{5}$ This increased strictness, which highlights the kickin-the-pants effect of takeovers, is not in the best interests of shareholders and represents a moral hazard stemming from the shareholders delegating to the board of directors the task of disciplining the CEO.

- The better the ex ante reputation for vigilance possessed by the board, the more lenient is the board with respect to dismissal of the manager. This result, which rests on the intermediate result of our model that the board will be more concerned with being displaced after a takeover when it has a poorer reputation [see Franks and Mayer (1991) for empirical support of this implication], has an interesting policy implication. When the board has a good reputation for vigilance, we can say that the internal corporate governance process works well. Somewhat counterintuitively, it is in such a circumstance that a takeover becomes more likely. The reason is that potential acquirers recognize that the board is prone to greater lenience due to the presence of the takeover market. Thus, even when internal corporate governance works well, there is an important role for takeovers. Conversely, there is a reduced role for takeovers as a mechanism to actually displace inefficient managers precisely when the board of directors has a weak reputation, i.e., when the internal corporate governance process does not work very well.

4. Kini, et al. (1992) report an abnormally high rate of turnover for both inside and outside directors, especially in "disciplinary" takeovers (involving CEO turnover).

5. If the board is vigilant and unconcerned about being displaced after a takeover, then the threat of a takeover makes the board more lenient in dismissing the manager. This lenience, due to the dominance of the substitution effect, is in the best interests of the shareholders. 
- An increase in the noisiness of the board's information about the manager causes the board to be stricter in dismissing the manager. Moreover, the acquirer becomes stricter in dismissing the board after a successful takeover. Thus, it is in the manager's best interest to give the board access to more accurate information.

The paper most closely related to the current analysis is that of Hirshleifer and Thakor (1994), who also examine substitution between takeovers and directorial oversight of managers. The main differences between that paper and this are that here: (1) we allow the acquirer to dismiss the board as well as the manager, leading to the kick-in-the-pants effect mentioned earlier, (2) we allow for varying degrees of precision in the information of the board, and (3) we examine the effect of board reputation and its characteristics on takeovers and on turnover. Difference (1) is important in that in reality it seems quite plausible that board members can expect to lose in a successful hostile takeover. Difference (2) provides policy implications for board dismissals of managers in different kinds of industries and firms in which the board is likely to have more or less accurate information. Difference (3) provides new empirical implications relating measurable board characteristics with the probabilities of takeover and turnover that are consistent with recent empirical evidence.

The rest of the paper is organized as follows. Section 2 describes the model. Section 3 derives the results, and Section 4 concludes.

\section{SUBSTITUTION BETWEEN BOARD DISMISSALS AND EXTERNAL TAKEOVERS}

\subsection{THE MODEL}

We examine the statistical problem faced by the board of directors and an external acquirer in inferring the ability of the current manager (CEO) in the absence of any moral hazard on the part of the manager. There are three dates, 0,1 , and 2, and the manager may be one of two types, good and bad, with prior probabilities of $\gamma \in(0,1)$ and $1-\gamma$ respectively at $t=0$. No one (including the manager) knows his type, and the prior probability $\gamma$ is common knowledge.

The payoff on the firm's investment project with a good manager is either $\$ 1$ with probability $P_{G}$, or 0 with probability $1-P_{G}$. The probability of success for the bad manager is $P_{B}<P_{G}$. Let $p_{s}$ denote the probability of success for a manager drawn randomly from the pool, where

$p_{s} \equiv \gamma p_{G}+(1-\gamma) p_{B}$. 
For simplicity, let the required investment for the project be zero at the start of each period (i.e., at date $t=0$ and at date $t=1$ ), and let the manager's wage also be zero. Similar results would obtain if the wage were positive.

The risk-free rate of discount is zero. There are no taxes, and we assume that the firm is all-equity financed. The sequence of events is as follows. At date $t=0$, the manager joins the firm, and selects a project, which has a greater probability of success if he is good than if he is bad. At date $t=1$ the first-period outcome (success or no success) is realized but not directly observed by anyone at that time. The board decides either to dismiss or to retain the manager. If the manager is dismissed, a new manager is selected randomly from the population. If the manager is retained, a potential acquirer decides whether to make a takeover attempt and replace the manager, and possibly the board as well. ${ }^{6}$ The manager selects a new project. Finally, at date $t=2$ the second-period project outcome is realized, and either old shareholders or the new owner receive the realized cash flows from both projects.

Motivated in part by the evidence of Walsh $(1988,1989)$ and of Martin and McConnell (1991) that posttakeover turnover rates in the top managements of firms that are takeover targets are significantly higher than pretakeover turnover rates, we assume that there may be a takeover bid at $t=1$ that will result in replacement of the manager if it is successful. Thus, takeovers in our analysis are hostile, in the sense that they are opposed by top management, ${ }^{7}$ in contrast with orderly transitions in which the manager and board both desire the takeover. Nonetheless, the board may accept a hostile takeover bid.

Let $x$ and $y$ be noisy indicators of the manager's ability that are privately observed by the board and by the potential outside acquirer, respectively. We assume that $x$ and $y$ are conditionally independent (but unconditionally correlated) positive indicators of ability, and that the monotone likelihood ratio property obtains, i.e.,

$\frac{f\left(w_{1} \mid G\right)}{f\left(w_{2} \mid G\right)}>\frac{f\left(w_{1} \mid B\right)}{f\left(w_{2} \mid B\right)}$ iff $w_{1}>w_{2}, \quad$ where $w=x, y$

6. The assumption that the board has the opportunity to remove the manager before the acquirer is based on the idea that the board receives its signal first, as a direct consequence of the board's monitoring of the firm's ordinary operations. The acquirer, on the other hand, must investigate in order to draw his signal. Hence his observation occurs only after a delay, possibly a substantial one.

7. Morck et al. (1988) show that friendly takeovers are associated with founding families intending to sell the firm, old managers desiring to retire, and other orderly transitions. These are beyond the scope of our analysis. 
It is straightforward to show that this implies that

$$
\frac{\partial \operatorname{Pr}(G \mid x)}{\partial x}>0, \quad \frac{\partial \operatorname{Pr}(G \mid y)}{\partial y}>0
$$

In other words, a higher value of either signal indicates a greater likelihood that the manager is good. ${ }^{8}$ The board of directors, upon observing $x$, decides whether to retain (RM) or to dismiss (DM) the manager. Let $\mathrm{A}$ denote an acquisition attempt, and let RB versus DB denote retention versus a dismissal of the board (by the acquirer). Then, if the manager is retained by the board, a potential acquirer observes $y$ and decides whether to acquire. We assume that an acquisition attempt is always successful. The model allows for the possibility that $x$ is not a sufficient statistic for $y$, i.e., that the board's information does not completely dominate the acquirer's. (See the related discussion in the Introduction.)

We further assume that $f(x \mid G)$ dominates $f(x \mid B)$ in the firstorder-stochastic-dominance sense. We make a similar assumption about $h(y \mid \tau)$, the conditional density function of the acquirer's signal, where $\tau \in\{G, B\}$ is the acquirer's type. We assume that $f(x \mid G)=$ $f(x \mid B)$ at only one $x$ and $h(y \mid G)=h(y \mid B)$ at only one $y$. The support of each density is $(-\infty, \infty)$, and the associated conditional distribution functions are $F(x \mid \tau)$ and $H(y \mid \tau)$, respectively.

There will exist a critical value $\hat{x}$ such that the board will dismiss the manager if $x<\hat{x}$. If $x \geq \hat{x}$, then the acquirer will form a posterior belief based on $y$ and on the fact that the manager was not dismissed by the board. This will lead to a critical value $\hat{y}$ below which the potential acquirer will make a bid for the firm.

Our focus is on the competing roles of board dismissal versus dismissal following acquisition. While a board performs a variety of functions, we believe that none is more relevant to the interaction between the board and an acquirer than the board's decision of whether to fire or retain the manager. We therefore abstract from details of bargaining in the takeover transaction process. Specifically, we assume that takeover occurs if and only if, based on the bidder's information, the takeover will generate an expected surplus. We do not examine how the surplus is divided, or the possibility that sequences of offers and rejections can communicate information between the bidder and the target.

8. It is most intuitive to view $x$ and $y$ as signals of the manager's success or failure, an event that is positively correlated with his ability but is not directly observed at $t=1$. 
For simplicity, we assume that the acquirer's ability is the same as a random drawing from the managerial pool. ${ }^{9}$ We consider two possible types of boards. With probability $\omega$, the board is vigilant, and with probability $1-\omega$, it is lax. A vigilant board balances costs and benefits in deciding whether to fire the manager as described below. A lax board never fires the manager. ${ }^{10} \mathrm{~A}$ high versus low $\omega$ can be thought of as corresponding at least partially with Weisbach's (1988) categorization of boards as inside- (management) versus outside-dominated.

There are, of course, other ways to model the board's quality. For instance, "quality" could refer to the board's ability to distinguish between good and bad managers or to the precision of the signals it observes about managerial performance. Our choice of modeling quality in terms of the board's alignment with the shareholders' interests is motivated by two considerations. First, much of the policy discussions about corporate governance have revolved around the vigilance of boards in their oversight function. ${ }^{11}$ Second, the empirical literature in this area has also focused on whether boards are inside- or outside-dominated, with the premise that the latter are more vigilant. ${ }^{12}$ Other notions of board quality may also be important. However, modeling multidimensional board quality would make the analysis hopelessly complex. We therefore focus on the most common notion of board quality in isolation. We will say more about this later.

In deciding whether to dismiss, a vigilant board is concerned both with maintaining managerial quality and with keeping its own perquisites. To distinguish between managerial quality at different points in time, we will use the subscapts 0 and 1 . That is, $\operatorname{Pr}\left(G_{0} \mid \cdot\right)$

9. Relaxing this assumption would not change the general nature of the results. If the acquirer has stochastically higher ability than a random drawing from the managerial pool, a board acting in the shareholders' best interest will dismiss the manager less often, in order to take advantage of the acquirer's potential superior ability.

10. This represents in an extreme fashion a situation in which there is uncertainty about how closely the board is aligned with management. Such alignment could be preference-based, as with board members with personal loyalties to the CEO, or reputation-based. A similar analysis could be provided in which a lax board sometimes dismisses, but is less willing to do so than a vigilant board. Apart from outright laxity, there are other reasons why a board might be reluctant to fire. For example, if the current board hired the manager, then board members could lose reputation by firing the manager, since this could be tantamount to conceding that the board made an error in the original hiring decision. This is similar to Boot's (1992) prediction that managers will often be reluctant to terminate unprofitable projects.

11. For example, see the cover story, "The CEO and the Board," in Business Week, September 15, 1997.

12. See, for example, Millstein and MacAvoy (1997). 
will refer to the probability that the manager is good at date $t=0$ (this refers to the incumbent manager, since the board and the acquirer have not made their replacement decisions yet), and $\operatorname{Pr}\left(G_{1} \mid \cdot\right)$ will refer to the probability that the manager is good at date $t=1$ after the replacement decisions of the board of directors and of the acquirer (who has successfully taken over the firm). We assume that the board's objective is to maximize the following expected utility:

$\operatorname{Pr}\left(G_{1} \mid x\right)+\mu \operatorname{Pr}($ board is not dismissed $)$.

The second probability is that of the board staying in charge, either because no acquisition takes place or because the acquirer retains the board. Directors' assumed desire to maintain managerial quality could arise from reputational considerations, share ownership, or a desire to build firm value in the expectation of possible future appointment as CEO. ${ }^{13}$ The board's concern with being retained could be based on perquisites of board membership (e.g., salary, prestige, inside information) or reputational considerations. $\mu>0$ represents an exogenously given weighting factor; it captures the importance the board attaches to not being dismissed. The higher the $\mu$, the more personally costly it is for the board to be dismissed.

The component of terminal firm value arising from the second project is assumed to be

$\kappa I\left(G_{1}\right)+\lambda I(V)$,

where $I\left(G_{1}\right)$ is an indicator function for the event that at $t=1$, the (new) manager in charge of the firm is good; it is 1 if the manager is good and zero otherwise. $I(V)$ is an indicator function for the event that the board is vigilant after the acquirer's decision of whether to replace the board. The constants $\kappa$ and $\lambda$ are positive weights, with $\kappa$ representing the contribution to firm value due to the manager being good rather than bad, and $\lambda$ is the contribution to firm value due to the board being vigilant rather than lax. The above expression implies that firm value is higher when the firm ends up with a good manager than with a bad one, and is higher when it ends up with a vigilant board than with a lax one. ${ }^{14}$ Since a lax board never fires, a dismissal

13. The evidence presented by Kaplan and Reishus (1990) indicates that the top executives of companies that do relatively poorly are less likely to receive additional outside directorships.

14. The value of board vigilance at date $t=1$ could be endogenized by adding an additional time period during which a vigilant board, if retained, helps maintain managerial quality after a takeover. 
reveals conclusively that the board is vigilant. We assume that there is a cost to the acquirer, $c$, of dismissing the board. This reflects losses of firm-specific and general expertise of incumbent board members and could also capture the search costs that would have to be incurred to find suitable replacements. Should the bidder acquire the target, it will therefore only dismiss the board if the bidder has observed a signal below some critical value $y^{*}$.

The board sets the critical value $\hat{x}$, taking into account that an acquirer may appear. So in close cases, the board, rather than dismissing, may retain the manager, knowing that if the acquirer draws a low $y$, he will replace the manager. In other words, the board can exploit the information of external acquirers by tilting toward retention of mediocre performers. It is in the marginal cases that the value of aggregating information with the potential external acquirer is the highest. We call this the substitution effect.

\subsection{SUMMARY OF KEY ASSUMPTIONS}

1. The manager's type affects firm value and is unknown to all, but prior beliefs about the manager's type are common knowledge.

2. An acquisition attempt occurs only if, according to the bidder's information, the takeover will generate an expected surplus. Details of how this surplus is divided between the bidding and target firms' shareholders are ignored. Thus, an acquisition attempt is always successful.

3. A board can be either vigilant or lax. A lax board never fires the manager, whereas a vigilant board's objective is to maximize a weighted average of the probability that the manager is good at $t=1$ and the probability that the board will not be fired.

4. Firm value in the second period is a weighted average of the manger's type and the board's type.

5. An acquirer faces a cost $c$ of firing the board.

6. Parameter values are assumed such that the acquirer will not retain the manager and fire the board.

\subsection{THE BOARD'S PROBLEM When THERE IS No EXTERNAL ACQUIRER}

Let $G_{0}$ denote the event that the incumbent manager is good (at $t=0$ ). If there were no outside acquirer, $\hat{x}$ would be determined as that value such that $\operatorname{Pr}\left(G_{0} \mid \hat{x}\right)=\gamma$, because for any lower value of $x$, the firm on average would do better drawing a new manager from the pool. We then invert in a Bayesian fashion to infer $\operatorname{Pr}\left(G_{0} \mid x\right)$ from 
$x$, as follows:

$\operatorname{Pr}\left(G_{0} \mid x\right)=\frac{f(x \mid G) \gamma}{f(x \mid G) \gamma+f(x \mid B)[1-\gamma]}$.

Now, $\hat{x}$ is the solution to

$\operatorname{Pr}\left(G_{0} \mid \hat{x}\right)=\gamma$

where $\operatorname{Pr}\left(G_{0} \mid x\right)$ is obtained from (5). We can now state the following result.

Lемма 1: Suppose that there is no external takeover market, so that the firm cannot be acquired. Then there exists a unique value of $x$, denoted by $\hat{x}^{U}$, such that the board dismisses the manager if $x<\hat{x}^{U}$, and retains him otherwise. This critical value $\hat{x}^{U}$ is determined by

$f\left(\hat{x}^{U} \mid G\right)=f\left(\hat{x}^{U} \mid B\right)$.

Proof. Follows directly from combining equations (5) and (6).

\subsection{Internal and External Control Methods: The OVERALL PROBLEM}

With external takeover threats, the board must take into account that the acquirer has some information not possessed by the board. The exact values for $\hat{x}, \hat{y}$, and $y^{*}$ can be solved by backward recursion. The acquirer, taking $\hat{x}$ as given, can solve for his optimal $\hat{y}$ and $y^{*}$. Then, moving backward, the board, taking $\hat{y}$ and $y^{*}$ as given, can solve for $\hat{x}$. We restrict parameters so that $y^{*}<\hat{y}$, so as to preclude the unlikely possibility that a bidder will retain the manager but dismiss the board. ${ }^{15}$ The following analysis demonstrates how $\hat{x}, \hat{y}$, and $y^{*}$ are endogenously determined by backward recursion.

Acquirer: Because of our assumptions that the acquirer has a manager of ability comparable to that of a new manager drawn randomly from the pool, and that an acquisition bid will be made only if the total expected surplus is assessed by the bidder as positive, the conditions for takeover and board dismissal are conveniently simplified. The acquirer solves for his optimal $\hat{y}$ taking $\hat{x}$ as given. Now $\hat{y}$ must satisfy

$\operatorname{Pr}\left(G_{0} \mid R M, y=\hat{y}\right)=\operatorname{Pr}(G \mid x \geq \hat{x}, y=\hat{y})=\gamma$,

15. This will hold if $c$ is sufficiently large. 
because for a value of $\hat{y}$ such that $\gamma$ (the likelihood that the acquirer's manager is good) is greater than the left-hand side (the likelihood that the incumbent manager is good), a slightly smaller value of $y$ would still generate benefits from acquisition. And if $\gamma$ were less than the left-hand side, then the acquirer would find it unprofitable to bid for the firm when $y=\hat{y}$. When an acquirer observes a signal $\hat{y}$, it will assess the likelihood of the manager being good as

$$
\begin{aligned}
& \operatorname{Pr}\left(G_{0} \mid x \geq \hat{x}, y=\hat{y}\right) \\
& \quad=\frac{\operatorname{Pr}(x \geq \hat{x} \mid G) h(\hat{y} \mid G) \gamma}{\operatorname{Pr}(x \geq \hat{x} \mid G) h(\hat{y} \mid G) \gamma+\operatorname{Pr}(x \geq \hat{x} \mid B) h(\hat{y} \mid B)[1-\gamma]} .
\end{aligned}
$$

We must also determine the acquirer's decision (given that he intends to acquire the target and replace management) of whether or not to remove the board, i.e., the value of $y^{*}$. In examining this decision, we need only consider the component of firm value derived from the board's contribution in the second project. Since $\lambda$ is the contribution to firm value of having a vigilant rather than a lax board, and the probability that board is vigilant is $\omega$, the expected value generated by the bidder replacing the board is

$\lambda \omega-c$,

where the first term indicates the expected firm value achieved by replacing the board with a random drawing from the pool of potential new board members, and the second term represents the cost of replacing the old board.

Let $V$ denote vigilance of the incumbent board. If the bidder retains the old board, the expected value generated by this decision is

$\lambda \operatorname{Pr}(V \mid y, \mathrm{RM})$,

the expected firm value achieved given the bidder's information about the vigilance of the old board. Thus, the bidder will replace the board if and only if

$\omega-\operatorname{Pr}(V \mid y, \mathrm{RM})>\frac{c}{\lambda}$.

The probability of the incumbent board being vigilant given that it retained the manager is increasing in $y$. When $y$ is low, there is a strong indication that the manager is bad, indicating that the board, 
having retained the manager, is probably lax. Thus, if the cost of removing the board is not too high, there will exist a critical value $y^{*}$ that equates the two sides of the above inequality. (If $c$ is too large, the board is never replaced.)

Board: The board dismisses the manager if $x<\hat{x}$ and retains him otherwise. $\hat{x}$ is determined by the condition that $\gamma$ (the probability of drawing a good manager after dismissing the old manager) must be equal to the sum of: (i) the probability of finding that the retained manager is good and that no takeover occurs, given that $x=\hat{x}$, and (ii) the probability that a takeover occurs and that the new manager is good. Let A denote an acquisition bid and NA no acquisition bid. The board makes its decision taking the bidder's strategy $\left(y^{*}, \hat{y}\right)$ as given. The board's expected utility from retaining the manager [by (3)] is

$$
\begin{aligned}
& \operatorname{Pr}\left(G_{0} \mid x, \mathrm{NA}, \mathrm{RM}\right) \operatorname{Pr}(\mathrm{NA} \mid x, \mathrm{RM})+\operatorname{Pr}(\mathrm{A} \mid x, \mathrm{RM}) \gamma \\
& +\mu \operatorname{Pr}(\mathrm{RB} \mid x, \mathrm{RM}) .
\end{aligned}
$$

If the board fires the manager, its expected utility [by (3)] is

$$
\gamma+\mu
$$

The critical value $\hat{x}$ at which the board is indifferent between retaining and dismissing is determined by equating (13) and (14).

We will now show that the threat of hostile takeover may cause the board to increase $\hat{x}$, and become tougher on the manager, owing to what we call the kick-in-the-pants effect. This effect arises from the board's desire to avoid being viewed as lax and be consequently dismissed by an acquirer. Whether a takeover threat increases or decreases $\hat{x}$ depends on the relative strengths of the substitution effect and the kick-in-the-pants effect. Our approach will be to examine how the board's decision rule $\hat{x}$ differs when $y$ is informative versus pure noise. When $y$ is pure noise, so that the acquirer receives no information about the manager, there is no benefit from the acquirer replacing the manager. Therefore, a takeover does not take place in this case, i.e., $\hat{y}=-\infty$. We then have the following proposition, whose proof appears in the Appendix.

\section{PROPOSITION 1:}

(i) If the cost of dismissing the board is sufficiently high, e.g., $c>\lambda \omega$, then takeover threats make the board more lenient, i.e., takeover threats increase $\hat{x}$. 
(ii) Suppose that $c<\lambda \omega$. Then there exists a cutoff

$$
\mu^{*}=\frac{\operatorname{Pr}\left(\mathrm{NA} \mid x=\hat{x}^{u}, \mathrm{RM}\right)[\operatorname{Pr}(G \mid \hat{x}, \mathrm{NA}, \mathrm{RM})-\gamma]}{1-\operatorname{Pr}\left(\mathrm{RB} \mid \hat{x}^{U}, \mathrm{RM}\right)}
$$

such that the following three results hold:

(1) After takeover, the board is dismissed with positive probability.

(2) If being dismissed is sufficiently costly for the board, that is, when $\mu>\mu^{*}$, then takeover threats make the board stricter, i.e., takeover threats reduce $\hat{x}$.

(3) When $\mu \leq \mu^{*}$, takeover threats make the board more lenient.

The threat of hostile takeover can cause a vigilant board to be either tougher or more lenient in its decision to dismiss a manager, i.e., $\hat{x}$ can either increase or decrease, as shown in Figure 1. The intuition is as follows. When the cost of dismissing the board, $c$, is sufficiently high, the board is relatively unconcerned about its own job security. In this case the presence of an external takeover market permits aggregation of information that is not directly available to the board. By dismissing the manager, the board precludes a takeover and therefore is unable to avail itself of (noisy) aggregation of its own information with that of a potential acquirer. What Proposition 1 asserts is that the information aggregation option has value, so that at

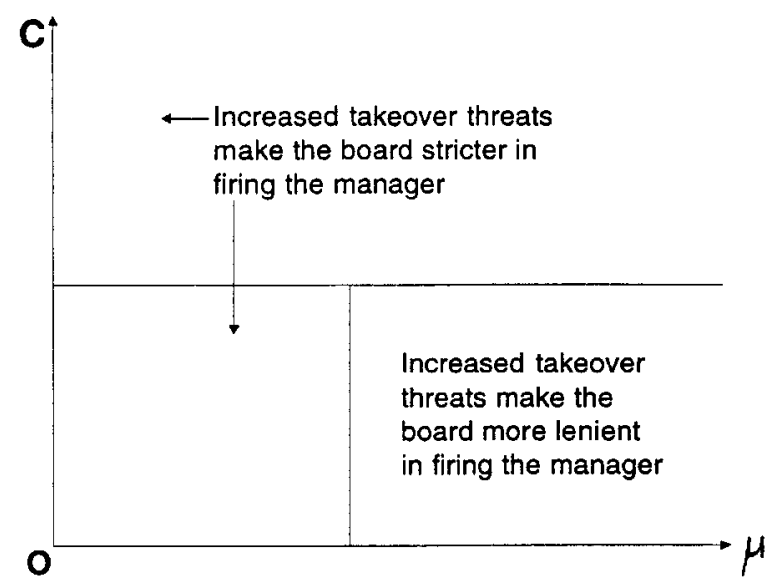

FIGURE 1. THE BOARD'S BEHAVIOR IN RESPONSE TO AN INCREASED THREAT OF A TAKEOVER 
the margin the board is inclined to retain the manager and let the acquirer decide whether the manager should be replaced, based on the information available to the acquirer. ${ }^{16}$ This lenience by the board (the substitution effect) is in the shareholders' best interests, since it means that the managerial dismissal-retention decision is more efficient. Cook (1996) provides evidence supporting such a substitution effect. He finds that thrifts that enjoyed regulatory protection from hostile takeovers were more likely to remove poorly performing CEOs (without being censured by the Office of Thrift Supervision) than those that were unprotected.

However, when the board perceives a significant threat to its own job security ( $c$ low, $\mu$ high), the cost to the board of retaining the manager goes up. Retention of the manager causes the acquirer to revise upward his belief that the board is lax, and hence the probability of board displacement increases. The effect of this threat may overwhelm the perceived value of information aggregation and cause the board to be stricter with the manager. Thus, this kick-in-the-pants effect gives rise to a form of moral hazard from the standpoint of the shareholders, since the board is being overly aggressive in firing the manager, relative to the shareholders' optimum. ${ }^{17}$ Of course, in this case as well as in the previous case, one has to be careful to take into account the simultaneity in the determination of the critical values for the board and the acquirer.

\subsection{THE EFFECTS OF THE BOARD'S REPUTATION AND PRECISION}

An important determinant of the board's behavior is its own reputation. Intuitively, members of a more reputable board should have less to fear personally from a takeover and should therefore attach greater

16. To understand why, suppose the board receives a signal $x$ just below $\hat{x}$, the critical value when there is no acquirer. With no acquirer, the board is virtually indifferent to whether to dismiss or retain. But if the acquirer's signal indicates that the manager is good, then it is better for the manager to be retained, and the reverse holds if the acquirer's signal is adverse. Thus, by retaining the manager and leaving the decision to the acquirer, the board can improve the expected outcome.

17. The kick-in-the-pants effect is undesirable from the shareholders' perspective, since it only affects the behavior of a vigilant board. If we had considered a richer variety of board types, possibly spanning the continuum between the "vigilant" and "lax" extremes considered here, then the kick-in-the-pants effect would induce a board of an intermediate type to behave in a manner that is closer to the shareholders' optimum. The qualitative nature of our principal results remains unchanged by this added complexity. 
weight to the substitution effect in dealing with the manager. From the shareholders' standpoint, then, the better the ex ante reputation of the board, the more closely aligned is the board's managerial dismissal-retention decision with the shareholders' best interest. A reputation for vigilance may be associated with numerous factors, such as representation of outside board members, ${ }^{18}$ shareownership by board members, and a history of disciplinary action against poorly performing managers. To examine the effect of reputation, let us view $\omega$, the probability that the board is vigilant, as the board's reputation index. Let $\omega_{r}$ be the average reputation index of a randomly selected board (taken as constant) and let $\omega_{i}$ be the reputation of the incumbent board of the specific firm under consideration. We then have the following result, whose proof appears in the Appendix.

Proposition 2: Suppose that $c<\lambda \omega$, so that after takeover the board is sometimes dismissed. Then, $\mu^{*}$, the cutoff defined in Proposition 1 , is increasing in the difference $\omega_{i}-\omega_{r}$. Thus, as $\omega_{i}-\omega_{r}$ increases, there is a smaller range of values of $\mu$ for which takeover threats make the board stricter in dealing with the manager. Likewise, as $\omega_{i}-\omega_{r}$ decreases, there is a larger range of $\mu$ values for which the board becomes stricter with the manager in response to a takeover threat.

If the board has a strong reputation for vigilance relative to its cohorts, incremental information about managerial performance that the acquirer receives will not cause him to lower his assessment of the board very much. In this case, $\mu$ (the cost the board attaches to being displaced), will have to be very high before the board becomes stricter in firing the manager when faced with a greater likelihood of a takeover. That is, there is a larger range of $\mu$ values for which takeover possibilities induce greater lenience by the board. On the other hand, a board with a weak reputation justifiably feels threatened by the potential for a downward revision in the acquirer's belief about the board's vigilance. This causes the kick-in-the-pants effect - greater strictness by the board in dealing with the manager-being dominant for a larger range of $\mu$ values. Since the acquirer recognizes this link between the board's behavior and its ex ante reputation, he will adjust his own behavior accordingly. Thus, counter to casual intuition, the acquirer will be more aggressive in his takeover behav-

18. Weisbach's (1988) evidence suggests that poor performance was associated with dismissal of the top manager among firms with outside-dominated boards, but not among firms with management-dominated boards. The evidence of Rosenstein and Wyatt (1990) also suggests that outside board members are more vigilant. 
ior when the board has a good reputation for vigilance and internal corporate governance is known to work well. ${ }^{19}$

Franks and Mayer (1991) have tested our prediction that less vigilant directors are more likely to be displaced after a takeover. Their evidence, based on hostile takeovers in the UK, supports this prediction.

Boards can differ not only in their reputation for vigilance, but also in the precision of their information about the performance of the manager. For example, some types of board members, such as university faculty or directors appointed for their political contacts, may not be able to evaluate managerial performance as easily as some practitioners with industry experience. Precision may also be industry-specific. In some industries the board may be able to monitor based on its own information about current costs and sales, while in others (such as those characterized by relatively risky long-term investments), this may be difficult. The board's precision may also be influenced by the relationship of the firm's performance to that of its industry. For instance, when an entire industry is doing poorly, it may be difficult for the board to disentangle the manager's contribution to his firm's poor performance. ${ }^{20}$ Finally, the board's precision may be affected by the manager's choice of internal auditing control systems.

We now examine what happens if the board's information about the manager becomes more noisy. To do this, we need to make some additional assumptions to focus on "reasonable" possibilities. By case 1 we mean the situation in which a takeover threat causes the board to be stricter. Let $x_{1}^{I}$ represent the board's critical value in this case. Note that $\hat{x}_{1}^{I}>\hat{x}^{U}$. By refer to case 2 we mean the situation in which a takeover threat makes the board more lenient. Let $\hat{x}_{2}^{I}$ represent the board's critical value in this case. Note that $\hat{x}_{2}^{I}<\hat{x}^{U}$.

We assume now that $f$ and $h$ are unimodal and symmetric densities. Let the random variable $z$ be a noisier version of $x$, and let $f^{*}(z \mid \tau)$ be the density function $z$, so that $f^{*}(z \mid \tau)$ represents a mean-preserving spread of $f(x \mid \tau)$ for each $\tau \in\{G, B\}$. Let the range of

19. The observation rests on the assumption that the board's reputation for vigilance is divorced from its ability to process ability-relevant information about the manager. If a board with a better reputation for vigilance is also able to more efficiently process information about the manager, then this result might be different. However, it is useful to separate the effects of reputation for vigilance and reputation for information processing; our analysis focuses on the former.

20. Morck et al. (1989) found that dismissals were more frequent among firms doing poorly relative to their respective industries, whereas hostile takeovers were more frequent among firms in poorly performing industries. 
$z$ be the same as the range of $x$. Define the values $x_{z}(\tau) \in(-\infty, \infty)$ as follows:

$x_{z}(G)=\min \left\{x \mid f(x \mid G)=f^{*}(z \mid G)\right\}$,
$x_{z}(B)=\max \left\{x \mid f(x \mid B)=f^{*}(z \mid B)\right\}$.

That is, $x_{z}(G)$ is the smaller of the two values of $x$ at which the density functions $f(\cdot \mid G)$ and $f^{*}(\cdot \mid G)$ intersect. Similarly, $x_{z}(B)$ is the larger of the two values of $x$ at which the density functions $f(\cdot \mid B)$ and $f^{*}(\cdot \mid B)$ intersect. These two points are shown in Figure 2. In this figure, $M_{G}$ and $M_{B}$ represent the means of the densities $f(x \mid G)$ and $f(x \mid B)$ respectively [and the means of the densities $f^{*}(z \mid G)$ and $f^{*}(z \mid B)$ as well]. We assume that $x_{z}(G) \in\left(\hat{x}^{U}, M_{G}\right), x_{z}(B) \in$ $\left(M_{B}, \hat{x}^{U}\right)$, so that $x_{z}(G)$ and $x_{z}(B)$ lie on either side of the intersection of the density functions for $B$ and $G$ (see Fig. 2). This has implications for the Bayesian inference process, as the discussion following Proposition 3 makes clear. Further, we assume that $z$ is sufficiently noisier than $x$ [the noisier is $z$, the greater is $x_{z}(B)$ and the smaller is $x_{z}(G)$ ], so that

$\hat{x}_{1}^{I} \in\left(x_{z}(G), M_{G}\right)$,

$\hat{x}_{2}^{I} \in\left(M_{B}, x_{z}(B)\right)$.

Figure 2 shows the relative positions of these points. We also assume that $y^{*}$ is such that

$\left.\frac{\partial h(y)}{\partial y}\right|_{y=y^{*}}>0$,

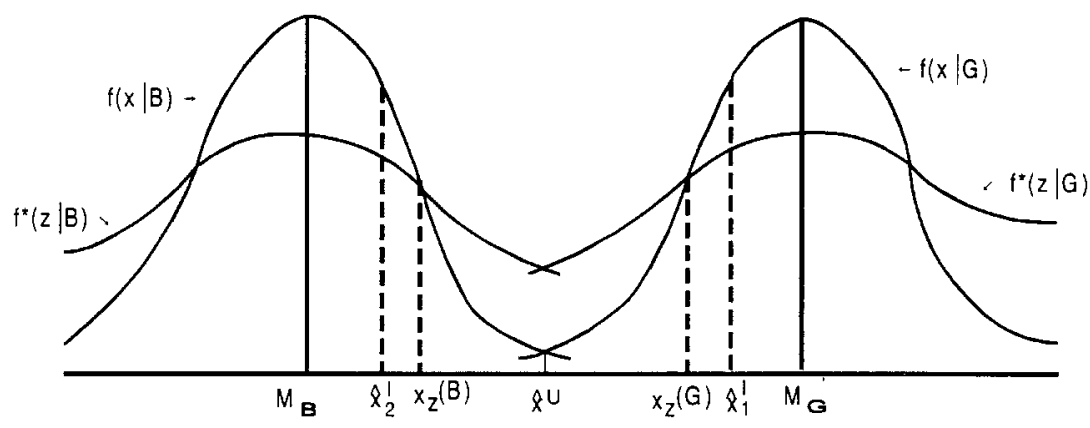

FIGURE 2. THE EFFECT OF NOISE ON THE BOARD'S SIGNAL 
where $h(y)$ is the unconditional density function of $y$, i.e., $h(y)=$ $\gamma h(y \mid G)+[1-\gamma] h(y \mid B)$. The reason for assuming that $y^{*}$ is on the upward-sloping portion of $h(y)$ is that an increase in $y^{*}$ then implies that, at the margin, observing a $y$ that equals the higher $y^{*}$ implies a greater probability that a board that retained a manager is vigilant (see the proof of Proposition 3). We now have the following results, whose proofs appear in the Appendix; the result in the lemma is used in the proof of the proposition.

LemMA 2: For sufficiently large $\gamma$ (sufficiently close to 1),

$\operatorname{Pr}\left(G_{0} \mid z \geq \hat{x}_{1}^{I}\right)<\operatorname{Pr}\left(G \mid x \geq \hat{x}_{1}^{I}\right)$

implies that

$\operatorname{Pr}\left(G \mid z \geq \hat{x}_{1}^{I}, y=\hat{y}\right)<\operatorname{Pr}\left(G \mid x \geq \hat{x}_{1}^{I}, y=\hat{y}\right)$.

Proposition 3: Assume that (16), (17), and (18) hold, that $c<\lambda \omega$, and that $\gamma$ is sufficiently large (close to 1 ). Then, in case 1 , when $\mu>\mu^{*}$, a critical value, the board becomes tougher in dealing with the manager as its information about the manager becomes noisier (i.e., the board sees $z$ rather than $x$ ). In case 2 , when $\mu<\mu^{*}$, if $\mu$ is sufficiently low, the board becomes more lenient in dealing with the manager as its information about the manager becomes noisier; whereas for $\mu$ close enough to $\mu^{*}$, greater noise leads the board to become tougher.

The intuition behind this proposition can be briefly seen as follows. In case 1 , suppose we held the critical value $\hat{x}_{1}^{I}$ fixed at the same value when the board observes $z$ as it is when the board observes $x$. Then, there are two effects worth noting. First, the greater noise in $z$ implies that, given a realization of $z$ in the neighborhood of $\hat{x}_{1}^{I}$, it becomes less likely that this signal emanated from a good rather than a bad manager. This reduces $\gamma^{\prime} \equiv \operatorname{Pr}(G \mid \hat{x}, N A, R M)-\gamma$ as defined in the proof of Proposition 1. This quantity is a measure of the value of the substitution effect toward retaining the manager. Second, if $\gamma$ is high enough, the unconditional probability that the manager will generate a performance signal that is at the critical value or exceeds it is lower under $z$ than under $x$. The reason is that a transition from $x$ to $z$ reduces $G^{\prime}$ s probability of generating that signal, but increases $B^{\prime}$ 's probability of doing so, and for high $\gamma$ (prior probability of $G$ ), the former effect dominates. Hence, when an acquirer observes that the manager has been retained, he believes that it is more likely that the board is lax (since it was a priori less likely that he would be retained by a vigilant board). The acquirer is 
therefore more likely to attempt a takeover and to dismiss the board after a takeover. This strengthens the kick-in-the-pants effect. Anticipating this, the board toughens its own standard. The reason why $\gamma$ cannot be too low is twofold. First, a high $\gamma$ is needed for the effect on $G$ to dominate, as indicated above. Second, too low a $\gamma$ would imply that the average quality of the managerial cohort group would be so low that it would not pay for even a vigilant board to fire the incumbent manager when $z<\hat{x}_{1}^{I}$ and replace him with a random draw from his cohort group.

In case 2 , the greater noise in $z$ means that the probability that a realization of $\hat{x}_{2}^{I}$ came from a good manager rather than a bad manager [i.e., $\operatorname{Pr}\left(G_{0} \mid\right.$ board's signal is in neighborhood of $\left.\hat{x}_{2}^{I}\right)-$ $\operatorname{Pr}\left(B_{0} \mid\right.$ board's signal is in neighborhood of $\left.\left.\hat{x}_{2}^{I}\right)\right]$ is greater under $z$ than under $x$. This is because under both the $x$ and the $z$ distributions, there is a greater likelihood that a realization in the neighborhood of $\hat{x}_{2}^{I}$ came from a bad manager than a good manager. This increases $\gamma^{\prime}$ and hence augments the substitution effect related to retaining the manager. Interestingly, however, the effect of noise on the kick-in-the-pants effect is the same in case 2 as it is in case 1. This is because if we hold $\hat{x}_{2}^{I}$ fixed, then (if $\gamma$ is sufficiently large) the probability that a manager can generate a signal $z$ that equals or exceeds $\hat{x}_{2}^{I}$ is still lower than the probability that he can generate a signal $x$ that equals or exceeds $\hat{x}_{2}^{I}$. Hence, retention of the manager leads the acquirer to believe that it is more likely that the board is lax.

It is important to note the reason why the impact of noise on the substitution effect is different across cases 1 and 2, while its impact on the kick-in-the-pants effect is the same. In assessing the substitution effect, the board observes the precise value of its own signal ( $x$ or $z$ ) and hence evaluates the (marginal) probability that a signal in an arbitrarily small neighborhood of that realization could have come from a good manager. Because $\hat{x}_{1}^{I}$ and $\hat{x}_{2}^{I}$ are on different sides of $\hat{x}^{U}$, the board's inferences are different across the two cases. In assessing the kick-in-the-pants effect, however, the board knows that the acquirer's information about the board's signal is coarser than the board's in that retention only means that either (1) the board is lax or that (2) it is vigilant and its signal was at least as great as the critical value. The acquirer's action is then based on evaluating the probability that the manager is good conditional on the signal value equaling or exceeding the critical value. Regardless of which side of $\hat{x}^{U}$ the board's critical value lies on and which distribution we are working with (that of $x$ or $z$ ), this probability is always greater for a good manager than for a bad manager. 
One interpretation of noise in this setting is that it represents coarseness in the internal accounting or information system used by the firm. The manager can't manipulate the information the board extracts about his performance from a given system, but he may be able to choose which system is set up. The analysis implies that it may be in the manager's interest to let the board have access to more accurate information about his performance. It also suggests that boards will tend to be more lenient in industries in which investments are long-term in nature and risky in the sense that they have outcomes that are difficult to predict. In such industries, boards will tend to wait and rely more on the information of potential acquirers to replace their managers.

Furthermore, Proposition 3 implies that the manager's interest in providing accurate information to the board becomes stronger as the board's reputation becomes weaker. We have not explicitly modeled a cost of information precision. Consider now a situation in which the manager bears a personal cost to providing information to the board, and this cost increases with the precision of the information. Then the analysis implies that the manager would wish to provide more accurate information to a less reputable board.

\section{CONCLUSION}

Our goal in this paper has been to address some policy issues related to the interaction between the internal mechanism for corporate control, as represented by actions of the board of directors, and the external mechanism for corporate control, as represented by takeovers. The issues that we have focused on have to do with the role of takeovers when corporate governance works well and when it does not, and the effects of the board's own reputation and the precision of its information about the manager on its behavior with respect to the manager.

We have assumed that the board serves as an agent of the shareholders, and like any agent it attends to its own welfare as well as that of the principal. This behavior gives rise to two effects created by the prospect of takeovers: a substitution effect whereby a takeover leads to better information about the manager through the noisy aggregation of the board's information with that of the acquirer, and a kick-in-the-pants effect whereby a takeover induces greater toughness in the board because of the possibility that it could be displaced following a successful takeover if it is viewed as being lax.

The simultaneous consideration of these two effects generates several implications about the interplay between internal and exter- 
nal mechanisms for corporate control. Perhaps the most compelling of all these implications is that, under very plausible conditions (the board is sufficiently concerned about being displaced after a takeover, and the cost of replacing the board is not too high for the acquirer), the kick-in-the-pants effect dominates when the board's reputation for vigilance is low. Thus, a weak board becomes stricter in firing the manager when faced with a greater likelihood of a takeover attempt on the firm. This implies, somewhat counterintuitively, that the need for external corporate governance to come into play is lower precisely when internal corporate governance does not work well.

This result has potentially serious repercussions for the belief that relying on the internal corporate governance provided by the board of directors rather than the external corporate governance provided by potential acquirers would help to ameliorate takeoverrelated investment distortions like myopia (Stein, 1988) and excessive conservatism (Hirshleifer and Thakor, 1992). Since boards may become more aggressive in dismissing managers when takeover threats are weak, investment distortions may be inescapable. It is important to note, however, that this result emerges in a setting in which the preferences of the board and its role in monitoring the manager are explicitly modeled.

Our analysis has assigned an important role to the board of directors as an intermediary between the shareholders and management. Although the board's interests may be more closely aligned with those of the shareholders than the manager's interests are, this alignment is imperfect in our model and in practice. In addition to the issues that we have analyzed, this raises interesting questions about the process by which boards of directors are chosen in publicly-held corporations and how their compensation packages are designed. These questions are beginning to be actively debated. There has recently been considerable pressure on public corporations to trim the compensation packages they offer their directors, and to make this compensation more performance-based..$^{21}$ A related issue, one that we have not considered, is the ownership of the firm

21. For example, an article in Business Week (Anon., 1995) states, "At more than two dozen companies this year, shareholders are seeking to strip directors of the generous retirement benefits they have been awarded routinely since the early 1980's. ... Board reform is probably on its way. Already, some companies have begun linking directors' pay to performance by awarding stock or options in lieu of or in addition to cash. And in early June, the National Association of Corporate Directors-a widely respected group whose members include CEOs and directors-is expected to release a sheaf of proposals on how directors should be paid." See also Byrne (1997), which states, " ... director retainers should be paid in stock. Extras, such as pensions, should be eliminated." 
possessed by the directors. Shivdasani (1993) has shown empirically that firms in which directors have smaller ownership stakes are more prone to receive hostile takeover bids. Our analysis suggests that a host of factors other than ownership structure are likely to be important. It would, however, be interesting to incorporate director ownership structure in our model.

\section{APPENDIX}

Throughout this Appendix, $G$ refers to the quality of the incumbent manager. Hence, the subscript 0 will be suppressed without ambiguity.

Proof of Proposition 1. The board's critical value for dismissing the manager is determined by equating (12) and (13) to obtain

$\operatorname{Pr}\left(G \mid \hat{x}^{I}, \mathrm{NA}, \mathrm{RM}\right) \operatorname{Pr}\left(\mathrm{NA} \mid \hat{x}^{I}, \mathrm{RM}\right)+\operatorname{Pr}\left(\mathrm{A} \mid \hat{x}^{I}, \mathrm{RM}\right) \gamma$

$$
+\mu \operatorname{Pr}\left(\mathrm{RB} \mid \hat{x}^{I}, \mathrm{RM}\right)=\gamma+\mu
$$

Superscripts $I$ have been added to denote critical values when $y$ is informative. If $y$ is uninformative, the critical value condition becomes

$\operatorname{Pr}\left(G \mid \hat{x}^{U}\right)=\gamma$,

where the superscript $U$ denotes the case of uninformative $y$. follows:

It is convenient to rearrange the condition for dismissal (A1) as

$\operatorname{Pr}(\mathrm{NA} \mid x, \mathrm{RM})[\operatorname{Pr}(G \mid x, \mathrm{NA}, \mathrm{RM})-\gamma]=\mu[1-\operatorname{Pr}(\mathrm{RB} \mid x, \mathrm{RM})]$,

where superscripts $I$ have been removed. The right-hand side of (A3) is decreasing in $x$ because higher $x$ implies a greater probability that the manager is good, so that, if he is retained by the board, there is a lower probability that the acquirer's signal $y$ is below his critical value for acquiring and dismissing the board.

We will show that the left-hand side of (A3) is monotonically increasing in $x$ in the neighborhood of the equilibrium threshold value $x=\hat{x}^{I}$. First $\operatorname{Pr}(\mathrm{NA} \mid x, \mathrm{RM})$ is also monotonically increasing 
with $x$, since higher $x$ indicates a good manager and thus leads to a lower probability that $y<\hat{y}^{I}$. Second, $\operatorname{Pr}(G \mid x, \mathrm{NA}, \mathrm{RM})$ is increasing in $x$. To see this, note that

$\operatorname{Pr}(G \mid x, \mathrm{NA}, \mathrm{RM})$

$$
\begin{aligned}
& =\frac{\operatorname{Pr}(G, x, y>\hat{y})}{\operatorname{Pr}(x, y>\hat{y})} \\
& =\frac{\operatorname{Pr}(x, y>\hat{y} \mid G) \operatorname{Pr}(G)}{\operatorname{Pr}(x, y>\hat{y})} \\
& =\frac{f(x \mid G) \operatorname{Pr}(y>\hat{y} \mid G) \operatorname{Pr}(G)}{f(x \mid G) \operatorname{Pr}(y>\hat{y} \mid G) \operatorname{Pr}(G)+f(x \mid B) \operatorname{Pr}(y>\hat{y} \mid B) \operatorname{Pr}(B)} \\
& =\frac{\operatorname{Pr}(y>\hat{y} \mid G) \operatorname{Pr}(G)}{\operatorname{Pr}(y>\hat{y} \mid G) \operatorname{Pr}(G)+\xi \operatorname{Pr}(y>\hat{y} \mid B) \operatorname{Pr}(B)}
\end{aligned}
$$

where $\xi=f(x \mid B) / f(x \mid G)$. By the monotone likelihood ratio property, $d \xi / d x<0$. It follows that $\operatorname{Pr}(G \mid x, \mathrm{NA}, \mathrm{RM})$ is increasing in $x$. It follows that the left-hand side of (A3) is monotonically increasing in $x$ in the region of $x$ where $\operatorname{Pr}(G \mid \hat{x}, \mathrm{NA}, \mathrm{RM})>\gamma$. This must be true in the neighborhood of the equilibrium threshold value $x=\hat{x}^{I}$, since the left-hand side is equal to the right-hand side a positive quantity; if $\operatorname{Pr}(G \mid \hat{x}, \mathrm{NA}, \mathrm{RM}) \leq \gamma$, the board would prefer to dismiss immediately.

Since the left-hand side of (A3) is monotonically decreasing in $x$ and the right-hand side is monotonically increasing in $x$ (aside from a set of $x$ values that are not feasible as equilibrium critical values), it follows that the equilibrium critical value is unique.

We now show that the board may be either more or less lenient in the informative case than in the uninformative case. Recall that the critical value in the uninformative case is determined by the condition (A2). Since the gain to retaining in the informative case [the difference between the left- and right-hand sides of (A3)] is monotonic in $x$ in the relevant region, we focus on the question of whether in the informative case, if $x$ is at the uninformative critical value $\hat{x}^{U}$, the board prefers to dismiss or retain. 
Let $\operatorname{Pr}(G \mid \hat{x}, \mathrm{NA}, \mathrm{RM})=\gamma+\gamma^{\prime}$, where $\gamma^{\prime}>0$. Then the difference between the left- and right-hand sides of (A3) becomes

$\Delta=\operatorname{Pr}\left(\mathrm{NA} \mid x=\hat{x}^{U}, \mathrm{RM}\right) \gamma^{\prime}-\mu\left[1-\operatorname{Pr}\left(\mathrm{RB} \mid \hat{x}^{U}, \mathrm{RM}\right)\right]$.

$\Delta$ can be either positive or negative. The manager is retained if $\Delta \geq 0$ and fired if $\Delta<0$. The critical $\mu^{*}$ at which the board's decision is the same as that without a takeover is given by $\Delta=0$, i.e., $\mu^{*}=\operatorname{Pr}(\mathrm{NA} \mid x$ $\left.=\hat{x}^{U}, \mathrm{RM}\right) \gamma^{\prime} /\left[1-\operatorname{Pr}\left(\mathrm{RB} \mid \hat{x}^{U}, \mathrm{RM}\right)\right]$. The first term in $\Delta$ encourages retention of the manager, and the second term encourages dismissal. On the one hand, the informativeness of $y$ causes a substitution effect, as reflected in the $\gamma^{\prime}$ term. $\gamma^{\prime}$ is the extra likelihood of a manager being good given that when he was retained, no takeover bid occurred. However, as reflected in the second term, informativeness also makes it possible that the board will be fired, which is an incentive for the board to be more strict.

If $\mu \leq \mu^{*}$, then the board cares primarily about being fired. By (A4) the second term dominates, so that the board becomes stricter in response to a greater takeover threat, the kick-in-the-pants effect. If $\mu \leq \mu^{*}$, then the substitution effect dominates, so that the board becomes more lenient in response to a greater takeover threat. If the cost of dismissal, $c$, is sufficiently high, the board will always be retained. By (12), if $c>\lambda \omega$, the board is never dismissed. Thus, the $\mu$ term vanishes, and the substitution effect dominates.

Proof of Proposition 2. The bidder replaces the board if (12) holds, with $\omega$ replaced with $\omega_{r}$. The left-hand side of (12) is increasing in $\omega_{r}$, and it is decreasing in $\omega_{i}$, because the subtracted probability is lower if the incumbent board has a poor reputation. Thus, the critical value for board dismissal, $\gamma^{*}$, increases as $\omega_{r}$ increases and decreases as $\omega_{i}$ increases, which means that in (A4), $\operatorname{Pr}(\mathrm{RB} \mid x, \mathrm{RM})$ decreases as $\omega_{r}$ increases and increases as $\omega_{i}$ increases. From the definition of $\mu^{*}$ in Proposition 1, it is clear that $\mu^{*}$ is increasing in $\operatorname{Pr}(\mathrm{RB} \mid x, \mathrm{RM})$. Moreover, $\operatorname{Pr}(\mathrm{RB} \mid x, \mathrm{RM})$ is increasing in $\omega_{i}-\omega_{r}$. Thus, $\mu^{*}$ is increasing in $\omega_{i}-\omega_{r}$.

Proof of Lemma 2. Since $\operatorname{Pr}\left(G \mid z \geq \hat{x}_{1}^{I}\right)<\operatorname{Pr}\left(G \mid x \geq \hat{x}_{1}^{I}\right)$, by Bayes's rule we have

$\frac{\operatorname{Pr}\left(z \geq \hat{x}_{1}^{I} \mid G\right) \operatorname{Pr}(G)}{\operatorname{Pr}\left(z \geq \hat{x}_{1}^{I}\right)}<\frac{\operatorname{Pr}\left(x \geq \hat{x}_{1}^{I} \mid G\right) \operatorname{Pr}(G)}{\operatorname{Pr}\left(x \geq \hat{x}_{1}^{I}\right)}$, 
which implies (upon multiplying both sides of the inequality with identical positive quantities)

$$
\begin{gathered}
\frac{\operatorname{Pr}\left(z \geq \hat{x}_{1}^{I} \mid G\right) h(y=\hat{y} \mid G) \gamma}{\operatorname{Pr}\left(z \geq \hat{x}_{1}^{I}\right)[h(y=\hat{y} \mid G)+h(y=\hat{y} \mid B)]} \\
<\frac{\operatorname{Pr}\left(x \geq \hat{x}_{1}^{I} \mid G\right) h(y=\hat{y} \mid G) \gamma}{\operatorname{Pr}\left(x \geq \hat{x}_{1}^{I}\right)[h(y=\hat{y} \mid G)+h(y=\hat{y} \mid B)]} .
\end{gathered}
$$

Now, the denominator on the left-hand side of (A5) can be written as

$$
\begin{aligned}
{[\operatorname{Pr}(z \geq} & \left.\left.\hat{x}_{1}^{I} \mid G\right) \gamma+\operatorname{Pr}\left(z \geq \hat{x}_{1}^{I} \mid B\right)[1-\gamma]\right][h(y=\hat{y} \mid G)+h(y=\hat{y} \mid B)] \\
= & \operatorname{Pr}\left(z \geq \hat{x}_{1}^{I} \mid G\right) h(y=\hat{y} \mid G) \gamma \\
& +\operatorname{Pr}\left(z \geq \hat{x}_{1}^{I} \mid B\right) h(y=\hat{y} \mid B)[1-\gamma] \\
& +\operatorname{Pr}\left(z \geq \hat{x}_{1}^{I} \mid G\right) h(y=\hat{y} \mid B) \gamma \\
& +\operatorname{Pr}\left(z \geq \hat{x}_{1}^{I} \mid B\right) h(y=\hat{y} \mid G)[1-\gamma] \\
= & \operatorname{Pr}\left(z \geq \hat{x}_{1}^{I}, y=\hat{y}\right)+\operatorname{Pr}\left(z \geq \hat{x}_{1}^{I} \mid G\right) h(y=\hat{y} \mid B) \gamma \\
& +\operatorname{Pr}\left(z \geq \hat{x}_{1}^{I} \mid B\right) h(y=\hat{y} \mid G)[1-\gamma]
\end{aligned}
$$

(where we have used the conditional independence of $z$ and $y$ ). Using similar steps, we can write the denominator of the right-hand side of (A5) as

$$
\begin{aligned}
\operatorname{Pr}(x & \left.\geq \hat{x}_{1}^{I}, y=\hat{y}\right)+\operatorname{Pr}\left(x \geq \hat{x}_{1}^{I} \mid G\right) h(y=\hat{y} \mid B) \gamma \\
& +\operatorname{Pr}\left(x \geq \hat{x}_{1}^{I} \mid B\right) h(y=\hat{y} \mid G)[1-\gamma] .
\end{aligned}
$$

We will now show that

$$
\begin{aligned}
\operatorname{Pr}(z \geq & \left.\hat{x}_{1}^{I} \mid G\right) h(y=\hat{y} \mid B) \gamma+\operatorname{Pr}\left(z \geq \hat{x}_{1}^{I} \mid B\right) h(y=\hat{y} \mid G)[1-\gamma] \\
< & \operatorname{Pr}\left(x \geq \hat{x}_{1}^{I} \mid G\right) h(y=\hat{y} \mid B) \gamma \\
& \quad+\operatorname{Pr}\left(x \geq \hat{x}_{1}^{I} \mid B\right) h(y=\hat{y} \mid G)[1-\gamma] .
\end{aligned}
$$


To establish (A8), we need to show that

$$
\begin{aligned}
& {\left[\operatorname{Pr}\left(x \geq \hat{x}_{1}^{I} \mid G\right)-\operatorname{Pr}\left(z \geq \hat{x}_{1}^{I} \mid G\right) h(y=\hat{y} \mid B) \gamma\right]} \\
& \quad>\left[\operatorname{Pr}\left(z \geq \hat{x}_{1}^{I} \mid B\right)-\operatorname{Pr}\left(x \geq \hat{x}_{1}^{I} \mid B\right)\right] h(y=\hat{y} \mid G)[1-\gamma]
\end{aligned}
$$

By using equations (7) and (8) and solving for $h(\hat{y} \mid G / h(\hat{y}, B)$, we can show that

$h(y=\hat{y} \mid G)<h(y=\hat{y} \mid B)$.

Thus, to establish (A8), it is sufficient to show that

$$
\begin{aligned}
& {\left[\operatorname{Pr}\left(x \geq \hat{x}_{1}^{I} \mid G\right)-\operatorname{Pr}\left(z \geq \hat{x}_{1}^{I} \mid G\right)\right] \gamma} \\
& \quad>\left[\operatorname{Pr}\left(z \geq \hat{x}_{1}^{I} \mid B\right)-\operatorname{Pr}\left(x \geq \hat{x}_{1}^{I} \mid B\right)\right][1-\gamma] .
\end{aligned}
$$

Rearranging this inequality implies that we need to show that

$$
\begin{aligned}
& \gamma \operatorname{Pr}\left(x \geq \hat{x}_{1}^{I} \mid G\right)+[1-\gamma] \operatorname{Pr}\left(x \geq \hat{x}_{1}^{I} \mid B\right) \\
& \quad>\gamma \operatorname{Pr}\left(z \geq \hat{x}_{1}^{I} \mid G\right)+[1-\gamma] \operatorname{Pr}\left(z \geq \hat{x}_{1}^{I} \mid B\right),
\end{aligned}
$$

which reduces to

$\operatorname{Pr}\left(x \geq \hat{x}_{1}^{I}\right)>\operatorname{Pr}\left(z \geq \hat{x}_{1}^{I}\right)$.

For $\gamma$ sufficiently high, this inequality will hold because (by symmetry combined with second-order stochastic dominance) $\operatorname{Pr}\left(x \geq \hat{x}_{1}^{I} \mid G\right)$ $>\operatorname{Pr}\left(z \geq \hat{x}_{1}^{I} \mid G\right)$. Thus, for a sufficiently high $\gamma$, (A8) obtains.

Now, (A8) implies that we can drop the second and third terms from both (A6) and (A7) and still not violate the inequality in (A5). That is, (A5) and (A8) jointly imply that

$$
\frac{\operatorname{Pr}\left(z \geq \hat{x}_{1}^{I} \mid G\right) h(y=\hat{y} \mid G) \gamma}{\operatorname{Pr}\left(z \geq \hat{x}_{1}^{I}, y=\hat{y}\right)}<\frac{\operatorname{Pr}\left(x \geq \hat{x}_{1}^{I} \mid G\right) h(y=\hat{y} \mid G) \gamma}{\operatorname{Pr}\left(x \geq \hat{x}_{1}^{I}, y=\hat{y}\right)},
$$

which means (by Bayes's rule) that

$\operatorname{Pr}\left(G \mid z \geq \hat{x}_{1}^{I}, y=\hat{y}\right)<\operatorname{Pr}\left(G \mid x \geq \hat{x}_{1}^{I}, y=\hat{y}\right)$. 
Proof of Proposition 3. The board's decision regarding the manager can be made on the basis of the following version of (A4):

$\Delta=\operatorname{Pr}(\mathrm{NA} \mid x, \mathrm{RM}) \gamma^{\prime}-\mu[1-\operatorname{Pr}(\mathrm{RB} \mid x, \mathrm{RM})]$.

As in the proof of Proposition 1, let

$\mu^{*}=\frac{\operatorname{Pr}\left(\mathrm{NA} \mid x=\hat{x}^{U}, \mathrm{RM}\right) \gamma^{\prime}}{1-\operatorname{Pr}\left(\mathrm{RB} \mid \hat{x}^{U}, \mathrm{RM}\right)}$.

At $\mu=\mu^{*}$, we have $\Delta=0$, so that the board's cutoff for firing the manager is $\hat{x}^{u}$, and the manager is fired if $x<\hat{x}^{u}$. Now consider case 1 , in which $\mu>\mu^{*}$. In this case, $\Delta<0$, so that making $\Delta=0$ requires that the cutoff $\hat{x}_{1}^{I}$ move to the right, i.e., $\hat{x}_{1}^{I}>\hat{x}^{U}$. Associated with each $\mu$ is a distinct cutoff that makes $\Delta=0$. Let $\hat{x}_{1}^{I}(\mu, x)$ be the cutoff associated with some $\mu<\mu^{*}$ when the board observes $x$. Clearly, $\hat{x}_{2}^{I}(\mu, x)<\hat{x}^{U} \forall \mu<\mu^{*}$. Similarly, let $\hat{x}_{2}^{I}(\mu, x)$ be the cutoff associated with some $\mu>\mu^{*}$ when the board observes $x$. Clearly, $\hat{x}_{2}^{I}(\mu, x)<\hat{x}^{U} \forall \mu<\mu^{*}$.

In much of what follows, we will drop the arguments of $\hat{x}_{1}^{I}$ and $\hat{x}_{2}^{I}$ to keep the notation clean.

We want to examine the sign of $\Delta$ when the board observes $z=\hat{x}_{1}^{I}$. Now let $\xi\left(x=\hat{x}_{1}^{I}\right) \equiv \operatorname{Pr}\left(x=\hat{x}_{1}^{I} \mid B\right) / \operatorname{Pr}\left(x=\hat{x}_{1}^{I} \mid G\right)$ and $\xi(z=$ $\left.\hat{x}_{1}^{I}\right) \equiv \operatorname{Pr}\left(z=\hat{x}_{1}^{I} \mid B\right) / \operatorname{Pr}\left(z=\hat{x}_{1}^{I} \mid G\right)$. It is evident from Figure 1 that $1>\xi\left(z=\hat{x}_{1}^{I}\right)>\xi\left(x=\hat{x}_{1}^{I}\right)>0$. Since $\operatorname{Pr}(G \mid x, \mathrm{NA}, \mathrm{RM})$ is decreasing in $\xi$, this implies that $\gamma^{\prime}\left(z=\hat{x}_{1}^{I}\right)<\gamma^{\prime}\left(x=\hat{x}_{1}^{I}\right)$, where $\gamma^{\prime}\left(z=\hat{x}_{1}^{I}\right) \equiv$ $\operatorname{Pr}\left(G \mid z=\hat{x}_{1}^{I}\right.$, NA, RM $)-\gamma$, and $\gamma^{\prime}\left(x=\hat{x}_{1}^{I}\right) \equiv \operatorname{Pr}\left(G \mid x=\hat{x}_{1}^{I}\right.$, NA, RM $)$ $-\gamma$. Next, note that

$$
\begin{aligned}
\operatorname{Pr}\left(\mathrm{NA} \mid z=\hat{x}_{1}^{I}, \mathrm{RM}\right)= & \operatorname{Pr}\left(y \geq \hat{y} \mid z=\hat{x}_{1}^{I}\right) \\
= & \operatorname{Pr}(y \geq \hat{y} \mid G) \operatorname{Pr}\left(G \mid z=\hat{x}_{1}^{I}\right) \\
& +\operatorname{Pr}(y \geq \hat{y} \mid B) \operatorname{Pr}\left(B \mid z=\hat{x}_{1}^{I}\right) .
\end{aligned}
$$

Now

$\operatorname{Pr}\left(G \mid z=\hat{x}_{1}^{I}\right)=\frac{f^{*}\left(\hat{x}_{1}^{I} \mid G\right) \gamma}{f^{*}\left(\hat{x}_{1}^{I} \mid G\right) \gamma+f^{*}\left(\hat{x}_{1}^{I} \mid B\right)[1-\gamma]}$.

Since $f^{*}\left(\hat{x}_{1}^{I} \mid G\right)<f\left(\hat{x}_{1}^{I} \mid G\right)$ and $f^{*}\left(\hat{x}_{1}^{I} \mid B\right)>f\left(\hat{x}_{1}^{I} \mid B\right)$, we see from (A11) that $\operatorname{Pr}\left(G \mid z=\hat{x}_{1}^{I}\right)<\operatorname{Pr}\left(G \mid x=\hat{x}_{1}^{I}\right)$ and $\operatorname{Pr}\left(B \mid z=\hat{x}_{1}^{I}\right)>\operatorname{Pr}\left(B \mid x=\hat{x}_{1}^{I}\right)$. 
From (A10) it follows that $\operatorname{Pr}\left(\mathrm{NA} \mid z=\hat{x}_{1}^{I}, \mathrm{RM}\right)<\operatorname{Pr}\left(\mathrm{NA} \mid x=\hat{x}_{1}^{I}, \mathrm{RM}\right)$, so long as it is the case that $\hat{y}$ either remains the same when the board observes $z$ as it is when the board observes $x$, or increases.

Now, $\hat{y}$ is determined by (8). Since $\operatorname{Pr}\left(G \mid z \geq \hat{x}_{1}^{I}\right)<\operatorname{Pr}\left(G \mid x \geq \hat{x}_{1}^{I}\right)$, we know from Lemma 2 that $\operatorname{Pr}\left(G \mid z \geq \hat{x}_{1}^{I}, y=\hat{y}\right)<\operatorname{Pr}\left(G \mid x \geq \hat{x}_{1}^{I}, y=\right.$ $\hat{y})$, which means that $\operatorname{Pr}\left(G \mid z \geq \hat{x}_{1}^{I}, y=\hat{y}\right)<\gamma$. Hence, when the board observes $z$, the acquirer sets $\hat{y}$ higher than when the board observes $x$. This confirms the condition on $\hat{y}$ needed for our earlier derivation of $\operatorname{Pr}\left(\mathrm{NA} \mid z=\hat{x}_{1}^{I}, \mathrm{RM}\right)<\operatorname{Pr}\left(\mathrm{NA} \mid x=\hat{x}_{1}^{I}, \mathrm{RM}\right)$ is valid (see last sentence of preceding paragraph).

We will now see how $\operatorname{Pr}\left(\mathrm{RB} \mid \hat{x}_{1}^{I}, \mathrm{RM}\right)$ is affected by noise. The indifference condition for retention of the board is that (12) hold as an equality. That is,

$\omega-\operatorname{Pr}\left(V \mid y=y^{*}, \mathrm{RM}\right)=\frac{c}{\lambda}$,

where

$\operatorname{Pr}\left(V \mid y=y^{*}, \mathrm{RM}\right)$

$$
=\frac{\left[h\left(y=y^{*}\right) \times \operatorname{Pr}\left(z \geq \hat{x}_{1}^{I}\right)\right] \omega}{\left[h\left(y=y^{*}\right) \times \operatorname{Pr}\left(z \geq \hat{x}_{1}^{I}\right)\right] \omega+h\left(y=y^{*}\right)[1-\omega]} .
$$

Now

$$
\begin{aligned}
\operatorname{Pr}\left(z \geq \hat{x}_{1}^{I}\right) & =\operatorname{Pr}\left(z \geq \hat{x}_{1}^{I} \mid G\right) \operatorname{Pr}(G)+\operatorname{Pr}\left(z \geq \hat{x}_{1}^{I} \mid B\right) \operatorname{Pr}(B) \\
& =\left[1-F^{*}\left(\hat{x}_{1}^{I} \mid G\right)\right] \gamma+\left[1-F^{*}\left(\hat{x}_{1}^{I} \mid B\right)\right][1-\gamma],
\end{aligned}
$$

where $F^{*}(\cdot \mid \tau)$ is the cumulative distribution function corresponding to the density $f^{*}(\cdot \mid \tau)$. Since $F^{*}\left(\hat{x}_{1}^{I} \mid G\right)>F\left(\hat{x}_{1}^{I} \mid G\right)$, it follows that for $\gamma$ high enough, $\operatorname{Pr}\left(z \geq \hat{x}_{1}^{I}\right)<\operatorname{Pr}\left(x \geq \hat{x}_{1}^{I}\right)$. From (A12) then, $\operatorname{Pr}(V \mid y=$ $\left.y^{*}, \mathrm{RM}\right)$ is lower when the board observes $z$ than when it observes $x$. Thus, as long as $c<\lambda \omega$ and $\partial h(y) /\left.\partial y\right|_{y=y^{*}}>0$, the acquirer must set a higher $y^{*}$ when the board observes $z$ than when the board observes $x$. This implies that $\operatorname{Pr}\left(\mathrm{RB} \mid z=\hat{x}_{1}^{I}, \mathrm{RM}\right)<\operatorname{Pr}\left(\mathrm{RB} \mid x=\hat{x}_{1}^{I}, \mathrm{RM}\right)$. It now follows from (A9) that $\Delta<0$ when evaluated at $z=\hat{x}_{1}^{I}$. Thus, $\hat{x}_{1}^{I}$ must move to the right, i.e., $\hat{x}_{1}^{I}(\mu, z)>\hat{x}_{1}^{I}(\mu, x) \forall \mu>\mu^{*}$, and in case 1 the board gets tougher when it observes $z$ than when it observes $x$.

Now consider case 2 , in which $\mu<\mu^{*}$. The desired result can be established by replicating the steps used above. In particular, we 
know that in this case the substitution effect works to make the board more lenient in response to takeover threats. What is noteworthy is that $F^{*}\left(\hat{x}_{2}^{I} \mid G\right)<F\left(\hat{x}_{2}^{I} \mid G\right)$ even in this case, so that with $\gamma$ sufficiently high, we still obtain $\operatorname{Pr}\left(z \geq \hat{x}_{2}^{I}\right)<\operatorname{Pr}\left(x \geq \hat{x}_{2}^{I}\right)$. Thus, $y^{*}$ is set higher by the acquirer when the board observes $z$ than when the board observes $x$, intensifying the kick-in-the-pants effect. This holds because at $\mu=\mu^{*}$, the kick-in-the-pants and substitution effects are perfectly balanced for $\mu$ sufficiently close to $\mu^{*}$. This increase will make the board tougher with the manager as its own evaluation of him gets noisier. On the other hand, for a sufficiently low $\mu$, the substitution effect dominates, so that the board becomes more lenient with the manager.

\section{REFERENCES}

Anon., 1995, "How Much Should it Take to Keep the Board on Board?" Business Week, April 17.

Black, B.S., 1992a, "Agents Watching Agents: The Promise of Institutional Investor Voices," UCLA Law Review, 39, 827-829.

_ 1992b, "The Value of Institutional Investor Monitoring: The Empirical Evidence," UCLA Law Review, 39, 944-951.

Boot, A., 1992, "Why Hang on to Losers: Divestitures and Takeovers," Journal of Finance, 47, 1201-1424.

Byrne, J.A., 1997, “The CEO and the Board," Business Week, September 15, 106-116.

Cook, O.D., 1996, “The Effect of Regulatory Oversight on Internal and External Mechanisms to Change Corporate Control," U.S. Office of Thrift Supervision.

DeAngelo, H. and L. DeAngelo, 1989, "Proxy Contests and the Governance of Publicly Held Corporations," Journal of Financial Economics, 23, 29-59.

Drucker, P.F., 1993, Management: Tasks, Responsibilities \& Practices, New York: Harper Business Press.

Fama, E. and M.C. Jensen, 1983, "Separation of Ownership and Control," Journal of Law and Economics, 26, 301-326.

Franks, J. and C. Mayer, 1991, "Hostile Takeovers in the UK and the Correction of Managerial Failure," Working Paper, London Business School, November.

Hirshleifer, D. and A.V. Thakor, 1992, "Managerial Conservatism, Project Choice and Debt," Review of Financial Studies, 5, 437-470.

— and —_ 1994, "Managerial Performance, Board of Directors and Takeover Bidding," Journal of Corporate Finance, 1, 63-90.

Kaplan, S.N. and D. Reishus, 1990, "Outside Directorships and Corporate Performance," Journal of Financial Economics 27, 389-410.

Kini, O., W. Kracaw, and S. Mian, 1992, “Corporate Takeovers, Firm Performance, and the Board of Directors," Mimeo, Penn State University, Smeal College of Business Administration, December.

Martin, K.J. and J.J. McConnell, 1991, "Corporate Performance, Corporate Takeovers and Management Turnover," Journal of Finance, 46, 671-688. 
Millstein, I.M. and P.W. MacAvoy, 1997, "The Active Board of Directors and Improved Performance of the Large Publicly-Traded Corporation," Working Paper 49, Series C, Yale School of Management, September.

Morck, R., A. Shleifer, and R.W. Vishny, 1988, "Characteristics of Hostile and Friendly Takeover Targets," in A.J. Auerbach, ed., Corporate Takeovers: Causes and Consequences, Chicago: University of Chicago Press.

,$- \ldots$, and ——1989, "Alternative Mechanisms for Corporate Control," American Economic Review, 79, 842-852.

Narayanan, M.P., 1985, "Managerial Incentives for Short-Term Results," Journal of Finance, 40, No. 5, 1469-1484.

Rosenstein, S. and J.G. Wyatt, 1990, “Outside Directors, Board Independence, and Shareholder Wealth," Journal of Financial Economics, 26, 175-192.

Shivdasani, A., 1993, "Board Composition, Ownership Structure, and Hostile Takeovers," Journal of Accounting and Economics, 16, 167-198.

Stein, J., 1988, "Takeover Threats and Managerial Myopia," Journal of Political Economy, 96, 61-80.

Walsh, J.P., 1988, "Top Management Turnover Following Mergers and Acquisitions," Strategic Management Journal, 9, 173-183.

—_, 1989, "Doing a Deal: Merger and Acquisition Negotiations and Their Impact upon Target Company Top Management Turnover," Strategic Management Journal, $10,307-322$.

Weisbach, M.S., 1988, "Outside Directors and CEO Tumover," Journal of Financial Economics, 20 (January-March), 461-492. 